\title{
Abnormalities of Carbamyl Phosphate Synthetase and Ornithine Transcarbamylase in Liver of Patients with Reye's Syndrome
}

\author{
FRANK SINATRA, TAKASHI YOSHIDA, MICHAEL APPLEBAUM, WILBERT MASON, NICHOLAS \\ J. HOOGENRAAD, AND PHILIP SUNSHINE(36) \\ Department of Pediatrics, Stanford University School of Medicine, University of Southern California School of \\ Medicine, Children's Hospital of Los Angeles, and University of California, San Francisco, California, USA
}

\section{Extract}

Urea cycle function was evaluated in liver obtained from six patients with Reye's syndrome and from five control subjects. Reye's syndrome patients demonstrated normal activities for the extramitochondrial portion of the urea cycle, but showed marked abnormalities of the mitochondrial enzymes, i.e., carbamyl phosphate synthetase (CPS) and ornithine transcarbamylase (OTC) (Tables 2, 3). CPS activity was reduced to less than $15 \%$ of control values in all four patients from whom tissues was obtained during the first $72 \mathrm{hr}$ after the onset of encephalopathy. Two patients from whom tissue was not obtained until after 9 days of symptoms showed no reduction in CPS activity. The OTC activity was also reduced ( $3-67 \%$ of control values) in the four patients from whom tissue was obtained early in the illness. In addition, greater than $60 \%$ reduction in $V_{\max }$ and $\mathrm{K}_{\mathrm{m}}$ for carbamyl phosphate was noted in all four patients in whom sample size permitted kinetic analysis, including both patients in whom CPS and OTC activity were not markedly reduced. The same kinetic abnormality as well as decreased CPS activity were experimentally produced in normal rat liver incubated in the presence of $1.0 \mathrm{mM}$ 4-pentenoic acid, a short chain fatty acid and known hepatic mitochondrial toxin (Table 4).

\section{Speculation}

Abnormalities of the mitochondrial portion of the urea cycle are a frequent occurrence in Reye's syndrome. This appears to be an acquired and reversible process that can probably be produced by a number of etiologic agents, of which endogenous or exogenous short chain fatty acids may be included.

In 1972, Kang and Gerald (17) pointed out some striking clinical and metabolic similarities between Reye's syndrome and acute exacerbations of congenital disorders of urea biosynthesis, and on the basis of serum amino acid patterns, predicted a defect in one or both of the mitochondrial enzymes of the urea cycle, i.e., CPS and OTC. After this report, several groups speculated about the role of defective urea cycle activity in the production of hyperammonemia in Reye's syndrome, and therapeutic regimes were proposed using urea cycle intermediates $(10,11,28)$. Brown et al. $(7,8)$ have subsequently reported a significant decrease in CPS and OTC activity in patients with Reye's syndrome and in reporting a case of Reye's syndrome with OTC deficiency, Thaler et al. (29) speculated as to the potential genetic origins of such defects.

In order to better understand the relationship between Reye's syndrome and defects in urea biosynthesis, we have examined the activities of the urea cycle enzymes in six patients with Reye's syndrome and in five control subjects, using liver biopsy and autopsy specimens. In addition, kinetic analyses were carried out for CPS and OTC in four of the patients with Reye's syndrome and in three members of the control group, in whom sample size was adequate, in an attempt to better define the enzymatic aberration.

Since a genetic etiology has been proposed for these defects, and in order to examine the possibility that such defects could be acquired, we also studied the effect, in vitro, of 4-pentenoic acid on the CPS and OTC activity of normal rat liver. Pentenoic acid is an analog of hypoglycin, the proposed etiologic agent in Jamaican vomiting sickness (26), and has been shown to produce a clinical picture similar to Reye's syndrome in rats $(9,12)$. Pentenoic acid is also a known hepatic mitochondrial toxin that might be expected to produce an acquired defect in urea cycle activity similar in nature to that which may occur in Reye's syndrome.

\section{PATIENTS}

Six patients with Reye's syndrome and five control patients were studied. The group with Reye's syndrome consisted of two males and four females ranging in age from 2 months to 11 years. Their clinical and laboratory findings are summarized in Table 1. All six patients demonstrated the classic prodromal illness followed by vomiting and rapid onset of encephalopathy, as described by Reye et al. (23). In addition, all six demonstrated elevated serum transaminases and prolonged clotting times. Serum ammonia was elevated in all five patients in whom it was obtained. None had significant hyperbilirubinemia or abnormal findings in their cerebrospinal fluid. Past history for symptoms suggestive of hyperammonemia was absent in all six patients and their families.

Liver was obtained from autopsy alone in three cases, from biopsy alone in two cases, and from both autopsy and biopsy in one case. Liver biopsy was performed, in all three cases, for histologic confirmation of the diagnosis before institution of the various forms of therapy and not primarily for purposes of this study. Informed consent was obtained before biopsy in each case.

Of the six patients studied four died. All four demonstrated autopsy findings consistent with Reye's syndrome. In the two survivors, histologic examination of liver obtained at biopsy showed diffuse, microvesicular steatosis without significant inflammation or necrosis. Both survivors are asymptomatic on 3 month follow-up examinations. Their serum ammonia concentrations were normal before discharge and have remained so during the follow-up period.

\section{MATERIALS AND METHODS}

Three biopsy and four autopsy samples of liver obtained from six patients with Reye's syndrome were compared with control human liver from two biopsy and three autopsy specimens. Control subjects consisted of five patients ranging in age from 2 
weeks to 11 years who died secondary to nonhepatic disease or who required liver biopsy for the diagnosis of non-Reye's syndromerelated disorders (choledochal cyst and intractable diarrhea of infancy). Autopsy samples from both Reye's syndrome and control groups were obtained within $2 \mathrm{hr}$ of death. As has been noted previously by Brown et al. (8), there were no significant differences between control liver obtained at autopsy and that obtained by percutaneous biopsy. Tissues were frozen immediately in liquid nitrogen and then stored at $-70^{\circ}$ until analyzed. Determinations were performed within 14 days of freezing in all cases. Activities were stable to within $5 \%$, when stored as whole liver, for up to 4 weeks after freezing in the case of CPS, and for up to 12 weeks in the case of OTC. Once homogenized, however, stability is markedly reduced, even when stored at $-70^{\circ}$ (CPS less than $24 \mathrm{hr}$ and OTC 36-48 hr). Therefore, all samples were stored as whole tissue until analyzed.

Urea cycle enzymes were assayed using 0.5 and $1.0 \%$ liver homogenates prepared in a solution of $5 \%(\mathrm{v} / \mathrm{v})$ glycerol, $1.0 \mathrm{mM}$ EDTA-tetra sodium salt, and $10 \%(\mathrm{v} / \mathrm{v})$ dimethyl sulfoxide. Activity of CPS was determined by the radiochemical assay of Levine and Kretchmer (19). The reaction mixture contained 1.0 $\mathrm{mM} \mathrm{NH}{ }_{4} \mathrm{Cl}, 21 \mathrm{mM}$ ATP, $100 \mathrm{mM} \mathrm{KCl}, 2.0 \mathrm{mM}$ acetyl glutamate, and $5.0 \mathrm{mM}\left(\mathrm{C}_{14}\right) \mathrm{NaHCO}_{3}$ (specific activity 2.19 $\mu \mathrm{Ci} / \mu \mathrm{mol})$ (31). The assay was carried out in $0.1 \mathrm{M}$ Na-Hepes buffer, $\mathrm{pH} 7.40$, in a total volume of $0.8 \mathrm{ml}$ and incubated for 20 $\min$ at $37^{\circ}$. The OTC activity was determined by a modification of the method of Goldstein et al. (15). In this method, the conversion of $\left[{ }^{14} \mathrm{C}\right]$ carbamyl phosphate was measured as follows: $50 \mu 10.5 \%$ liver homogenates were incubated for $15 \mathrm{~min}$ at $37^{\circ}$ in a total volume of $0.5 \mathrm{ml}$. The concentration of $\left[{ }^{14} \mathrm{C}\right]$ carbamyl phosphate was $0.4 \mathrm{mM}$ (specific activity $1.0 \mu \mathrm{Ci} / \mu \mathrm{mol}$ ) (31), the concentration of ornithine was $10 \mathrm{mM}$, and the reaction was carried out in $0.1 \mathrm{M}$ Tris buffer, $\mathrm{pH}$ 7.0. The reaction was terminated by adding $100 \mu 150 \%(\mathrm{w} / \mathrm{v})$ trichloroacetic acid. After heating for $5 \mathrm{~min}$ in a boiling water bath, the excess ${ }^{14} \mathrm{CO}_{2}$ was removed by adding crushed Dry Ice. After centrifugation for $10 \mathrm{~min}$ at $2,000 \times \mathrm{g}$, the entire supernatant was transferred to a vial containing $10 \mathrm{ml}$ liquid scintillation solution containing Triton X-114 (2) and $\left[{ }^{14} \mathrm{C}\right]$ carbamyl phosphate incorporated was counted using a Beckman LS 233 liquid scintillation spectrometer (32).

Activities of nonmitochondrial urea cycle enzymes (argininosuccinic acid synthetase, argininosuccinic acid lyase, and arginase) were determined by the methods of Schimke (25) and urine orotic acid excretion by the method of Adachi et al. (1) as modified by Goldstein et al. (15). Protein determinations were performed by the method of Lowry et al. (21).

The effect of 4-pentenoic acid (33) and acetylsalicylic acid on CPS and OTC activity was examined in normal rat liver. A $0.5-1.0 \%$ homogenate of liver tissue obtained from 20-day-old male Wistar rats was prepared as described above and mixed with an equal volume of either 4-pentenoic acid, acetylsalicylic acid, or distilled water. The mixtures were allowed to stand at room temperature for $0-30 \mathrm{~min}$, after which a $50-\mu \mathrm{l}$ aliquot was added to the reagent mixture and the reaction started. The CPS and OTC activities were then determined by the methods described above. The final concentrations of 4-pentenoic acid and acetylsalicylic acid were $1.0 \mathrm{mM}$ and $2.0 \mathrm{mM}$, respectively.

Kinetic analyses were carried out on both human and animal tissues. Apparent $K_{m}$ and $V_{\max }$ values were obtained from Lineweaver-Burk plots constructed from initial velocity measurements analyzed with an IBM 360/50 system with on-line communication and programs in PL/ACME language.

\section{RESULTS}

\section{CLINICAL STUDIES}

CPS activity was reduced to less than $15 \%$ of control values in four of the six patients with Reye's syndrome (Table 2). Kinetic analyses on two patients from this group showed reduced $V_{\max }$ and

Table 1. Clinical summar ${ }^{1}$

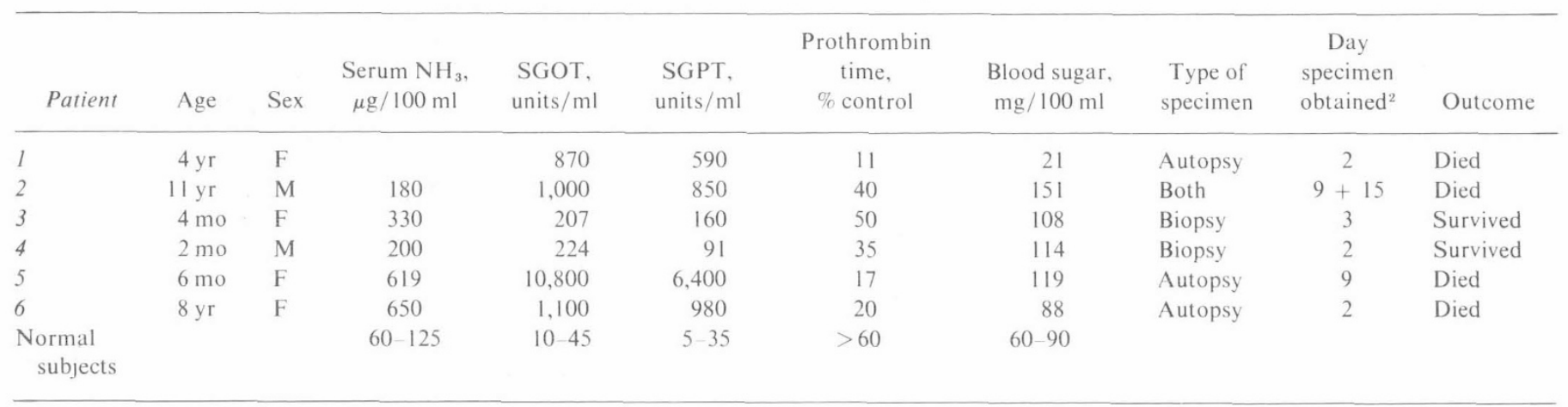

${ }^{1}$ SGOT serum glutamine oxaloacetic transaminase; SGPT; serum glutamic-pyruvic transaminase.

${ }^{2}$ Measured from the onset of encephalopathy.

Table 2. Carbamyl phosphate synthetase activity

Carbamyl phosphate synthetase

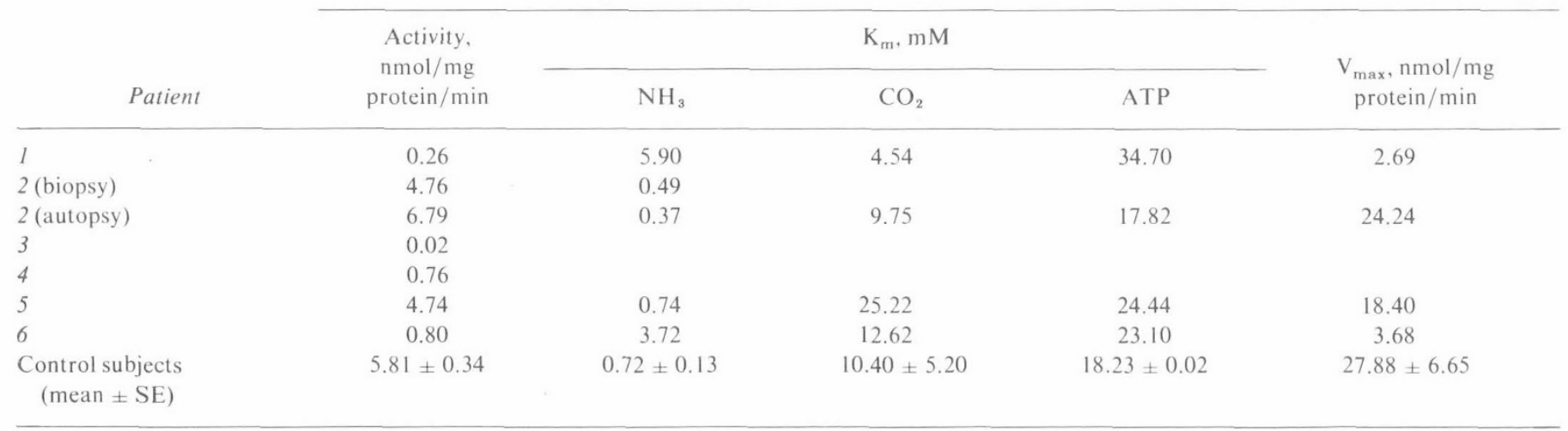


Table 4. Effect of pentenoic acid on carbamyl phosphate synthetase (CPS) and ornithine transcarbamylase activity (OTC) in rat liver ${ }^{1}$

\begin{tabular}{lcccc}
\hline & CPS & \multicolumn{3}{c}{ OTC } \\
\cline { 2 - 5 } & $\begin{array}{c}\text { Activity, } \\
\mathrm{nmol} / \mathrm{mg} \\
\mathrm{protein} / \mathrm{min}\end{array}$ & $\begin{array}{c}\text { Activity, } \\
\mathrm{nmol} / \mathrm{mg} \\
\mathrm{protein} / \mathrm{min}\end{array}$ & $\begin{array}{c}\mathrm{K}_{\mathrm{m}}(\text { carbamy } \\
\left.1-\mathrm{PO}_{4}\right), \mathrm{mM}\end{array}$ & $\begin{array}{c}\mathrm{V}_{\max }, \\
\mathrm{nmol} / \mathrm{mg} \\
\mathrm{protein} / \mathrm{min}\end{array}$ \\
\hline $\begin{array}{c}\text { Pentenoic } \\
\text { acid }\end{array}$ & 7.8 & 310 & 1.51 & 1,408 \\
\begin{tabular}{c} 
Controls \\
\hline
\end{tabular} & 16.4 & 368 & 3.42 & 3,267 \\
\hline
\end{tabular}

${ }^{1}$ Results represent the mean of triplicate determinations performed on each of three livers obtained from 20-day-old male Wistar rats. Liver from each animal was assayed for CPS and OTC activity after a 15-min preincubation period with and without 4-pentenoic acid.

acid. The velocity curve for carbamyl phosphate was similar to that seen in the patients with Reye's syndrome, and showed a reduced $\mathrm{V}_{\max }$ and $\mathrm{K}_{\mathrm{m}}$ for carbamyl phosphate (Fig. 3). As in the case of CPS, the effect on OTC was noted only after preincubation for at least $15 \mathrm{~min}$. The effect of preincubation time with 4-pentenoic acid on OTC activity is shown in Figure 4. There was no change in OTC or CPS activity when $2.0 \mathrm{mM}$ acetylsalicylic acid was used in place of 4-pentenoic acid.

\section{DISCUSSION}

Defective urea cycle function is an attractive way to explain many of the pathophysiologic events observed in patients with Reye's syndrome. Such defects could explain the hyperammonemia, encephalopathy, and amino acid patterns which have been reported (16). A defect in one or both of the mitochondrial enzymes of this pathway is even more attractive in view of the ultrastructural changes in the hepatocyte mitochondria described by Partin et al. (22).

Our studies confirm the existence of such defects and are in accord with the predictions of Kang and Gerald (17) and the subsequent investigation by Brown et al. $(7,8)$. The defect in CPS and OTC activity appears most prominent in the first $72 \mathrm{hr}$ of disease and may return to normal, or near normal, values during recovery, or at the time of death in cases where death followed a prolonged period of progressive neurologic dysfunction. Previously abnormal liver function studies had also returned to normal by the time of death in this latter group. We have also demonstrated a more persistent kinetic abnormality in OTC function in patients with Reye's syndrome in which $\mathrm{V}_{\max }$ and $\mathrm{K}_{\mathrm{m}}$ for carbamyl phosphate are reduced, even in cases where overall OTC activity is not greatly reduced. This abnormality was present up to 15 days after the onset of symptoms. In addition, the same kinetic abnormality as well as decreased CPS activity was reproduced in normal rat liver incubated in the presence of a short chain fatty acid (4-pentenoic acid). The failure of previous studies by Glasgow and Chase (13) to demonstrate direct inhibition of CPS and OTC by 4-pentenoic acid is most likely a result of the method employed, in which 4-pentenoic acid was not allowed to preincubate with the homogenate, or liver slice, before determination of enzyme activity. As shown in Figure 4, the ability of 4-pentenoic acid to produce inhibition of OTC activity is dependent on preincubation with the liver homogenate, suggesting that a metabolite of 4-pentenoic acid may be responsible. Attempts are now underway to isolate and identify such metabolites.

The changes we have described involve both enzymes of the mitochondrial portion of the urea cycle. In addition, the time course for these changes appears similar to that observed for the mitochondrial changes, being most marked in the first $72 \mathrm{hr}$ after the onset of encephalopathy (22). Serial determinations in a given patient would be needed to confirm this impression. These findings, however, and the observation that the changes can be reproduced in normal rat liver through the use of a known hepatic mitochondrial toxin suggests that an alteration in mitochondrial integrity may be responsible for these defects.

A genetic origin, as proposed by Thaler et al. (29), is an alternative explanation for these defects, but appears unlikely in the majority of cases. The observation that more than one enzyme is affected, the general lack of repeated episodes in an individual patient (18), and the apparent epidemic clustering of some of the cases $(20,24)$, argue against a genetic etiology. In addition, the survivors in this series had activities of CPS, which if persistent, would most likely have been incompatible with life.

In view of these observations, one might speculate as to the potential role of short chain fatty acids, like 4-pentenoic acid, in the pathogenesis of Reye's syndrome. These compounds have been shown to be potent inhibitors of fatty acid oxidation and gluconeogenesis $(3,7)$. The effect of such inhibition is fatty acid accumulation and subsequent re-esterification into neutral fats, as well as hy-

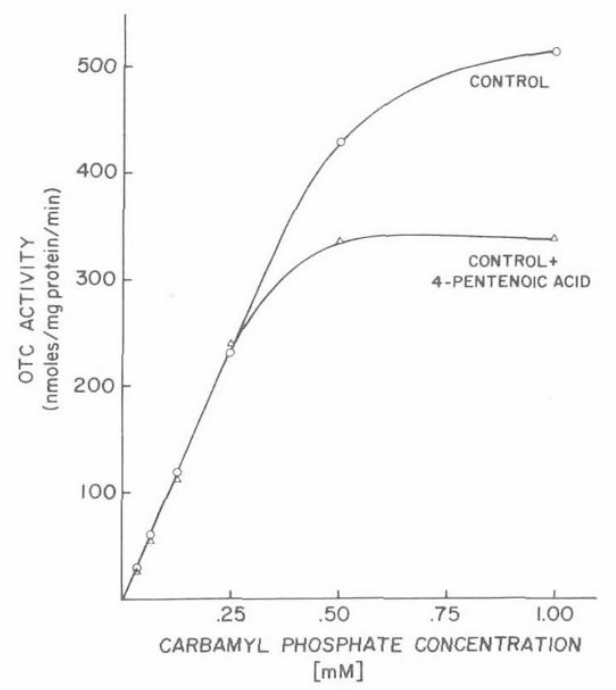

Fig. 3. Effect of 4-pentenoic acid on the ornithine transcarbamylase $(O T C)$ velocity curve with respect to carbamyl phosphate in normal rat liver. Homogenates were preincubated for $15 \mathrm{~min}$ at room temperature in the presence of $1.0 \mathrm{mM}$ 4-pentenoic acid. Control homogenates were preincubated for the same time period in the presence of an equal volume of distilled water. Ornithine concentration was constant $(10 \mathrm{mM})$ and carbamyl phosphate varied as shown.

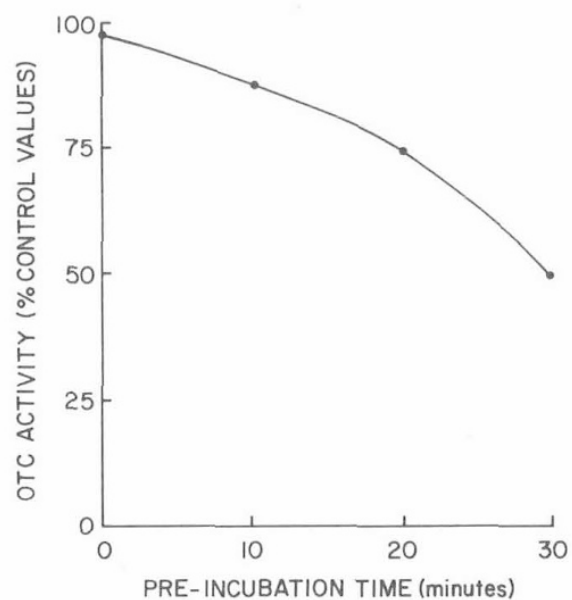

Fig. 4. Effect of preincubation time on in vitro inhibition of ornithine transcarbamylase $($ OTC) activity in normal rat liver by 4-pentenoic acid. Activity is compared with control liver from the same animals, preincubated for the same time in an equal volume of distilled water, and is expressed as percentage of control values. 
poglycemia. The best available data on the hypoglycemia that may accompany Reye's syndrome, also suggests a defect in gluconeogenesis (14). In addition, this group of compounds has been shown to produce a Reye's-like syndrome in both humans and rats $(9,12)$. including hyperammonemia and ultrastructural changes not greatly dissimilar from those described in patients with Reye's syndrome (4). Brown and Madge $(5,6)$ have suggested a potential endogenous source of such compounds in the form of abnormal and excessive lipolysis with increased free fatty acid mobilization. and Zieve et al. (30) have demonstrated potentiation of ammonium chloride induced hepatic coma by short chain fatty acids.

\section{SUMMARY}

Defects in the mitochondrial portion of the urea cycle appear to be a relatively consistent finding in patients with Reye's syndrome. Our studies suggest that the defects may be most prominent during the first $72 \mathrm{hr}$ of disease and may return to normal later in the illness. In addition, OTC demonstrated a more persistent abnormality in kinetic properties, being present up to 15 days after the onset of symptoms. These changes in CPS and OTC function were experimentally reproduced in normal rat liver by a short chain fatty acid (4-pentenoic acid).

\section{REFERENCES AND NOTES}

1. Adachi, T., Tanimura, A., and Asahina, M.: A colórimetric determination of orotic acid. J. Vitaminol., 9: 217 (1963).

2. Anderson, L. E., and McClure, W. O.: An improved scintillation cocktail of high solubilizing power. Anal. Biochem., 51: 173 (1973).

3. Bressler, R., and Brenderl, K.: The mechanism of the toxicity of 4-pentenoic acid Trans. Ass. Amer. Phys., 82: 153 (1969).

4. Brooks, S. E. H., and Audretsch, J. J.: Studies on hypoglycin toxicity in rats. I. Changes in hepatic ultrastructure. Amer. J. Pathol. 59: 161 (1970).

5. Brown, R. E., and Madge, G. E.: Fatty acids and metabolic disturbance in Reye's syndrome. Arch. Pathol. 94: 475 (1972).

6. Brown, R. E., Madge, G. E., and Schiller, H. M.: Observations on the pathogenesis of Reye's syndrome. Southern Med. J., 64: 942 (1971).

7. Brown, T., Brown. H., Lansky, L., and Hug, G.: Carbamyl phosphate synthetase and ornithine transcarbamylase in liver of Reye's syndrome. N. Engl, J. Med., 291: 797 (1974)

8. Brown, T., Hug, G., Bove, K., Brown, H., and Lansky, L.: Reye's syndrome. Lancet, ii: 716 (1974).

9. Colon, A. R., and Sandberg, D. H.: Viral potentiation of hepatic mitochondrial toxins in an experimental Reye's syndrome. Clin. Res., 21: 111 (1973).

10. DeLong, G. R., Glick, T. H., and Shannon, D. C.: Citrulline for Reye's syndrome. N. Engl. J. Med., 290: 1488 (1974).

11. Glasgow, A. M., and Chase, H. P.: Citrulline for Reye's syndrome. N. Engl. J. Med., 291: 421 (1974).

12. Glasgow, A. M., and Chase, H. P.: Production of the features of Reye's syndrome in rats with 4-pentenoic acid. Pediat. Res., 9: I33 (1975).
13. Glasgow, A. M., and Chase, H. P.: Inhibition of urea synthesis by 4-pentenoic acid. Biochem. Biophys. Res. Commun., 62: 362 (1975).

14. Glasgow, A. M., Cotton, R. B., and Dhiensiri. K.: Reye syndrome. III. The hypoglycemia. Amer. J. Dis. Child., I25: 809 (1973).

15. Goldstein, A. S., Hoogenraad, N. J., Johnson, J. D., Fukunaga, K., Swierczewski, E., Cann, H. M., and Sunshine, P.: Metabolic and genetic studies of a family with ornithine transcarbamylase deficiency. Pediat. Res., 8: 5 (1974).

16. Hilty, M. D., Romshe. C. A., and Delameter. P. V.: Reye's syndrome and hyperaminoacidemia. J. Pediat., 84: 362 (1974).

17. Kang. E. S., and Gerald, P. S.: Hyperammonemia and Reye's syndrome. N. Engl. J. Med., 286: 1216 (1972).

18. Kumar, V., and Chandrasekaran, R.: Reye's syndrome. Lancet, ii: 1203 (1974).

19. Levine, R. L., and Kretchmer. N.: Conversion of carbamoyl phosphate to hydroxyurea: An assay for carbamoyl phosphate synthethase. Anal. Biochem.. 42: 324 (1971).

20. Linnemann, C. C., Shea, L., Kauffman, C. A., Schiff, G. M., Partin, J. C., and Schubert, W. K.: Association of Reye's syndrome with viral infection. Lancet. ii: 179 (1974).

21. Lowry, O. H., Rosebrough, N. J., Farr, A. L., and Randall, R. J.: Protein measurement with the Folin phenol reagent. J. Biol. Chem., 193: 265 (1951).

22. Partin, J. C., Schubert, W. K., and Partin, J. S.: Mitochondrial ultrastructure in Reye's syndrome (encephalopathy and fatty degeneration of the viscera). N. Engl. J. Med., 285: 1339 (1971).

23. Reye, R. D. K., Morgan, G., and Baral, J.: Encephalopathy and fatty degeneration of the viscera, a disease entity in childhood. Lancet, $\ddot{i}: 749$ (1963).

24. Reynolds, D. W. Riley, H. D., LaFont, D. S., Vorse, H., Stout, L. C and Carpenter, R. L.: An outbreak of Reye's syndrome associated with influenza-B. J. Pediat., 80: 429 (1972).

25. Schimke, R. R.: Adaptive characteristics of urea cycle enzymes in the rat. J. Biol. Chem., 237: 459 (1962).

26. Tanaka, K., Isselbacher, K. J., and Shih. V.: Isovaleric and methylbutyric acidemias induced by hypoglycin A: Mechanism of Jamaican vomiting sickness. Science, 175: 69 (1972).

27. Toews, C., Ruderman, N., Lowry, C., Shafrir, E., and Cahill, G. F., Jr.: The mechanism of inhibition of gluconeogenesis by pent-4-enoic acid. Fed. Proc., 28: 411 (1969).

28. Thaler, M. M.: Role of ornithine transcarbamylase in Reye's syndrome. N. Engl. J. Med., 291: 797 (1974).

29. Thaler, M. M., Hoogenraad, N. J., and Boswell, M.: Reye's syndrome due to novel protein-tolerant variant of ornithine transcarbamylase deficiency. Lancet, ii: 438 (1974).

30. Zieve, F. J., Zieve, L., Doizaki, W. M., and Gilsdorf, R. B.: Syngergism between ammonia and fatty acids in the production of coma: implications for hepatic coma. J. Pharmacol. Exp. Ther., 191: 10 (1974).

31. New England Nuclear Corporation, Boston. Mass

32. Beckman Instruments, Palo Alto, Calif.

33. ICN, K \& K Laboratories, Inc., Irvine, Calif.

34. The authors are greatly indebted to Marilyn Boswell for her able technical assistance, to Virginia Pitts for her artistic contribution, to Mery Clausen for the preparation of the manuscript, and especially to Drs. Henry N. Edmunds and John D. Johnson for their critical review and helpful suggestions.

35. This investigation was supported by Grant HD-00049 from the National Institutes of Health, by Grants HD-02147, HD-00391, and RR-0008I from the General Clinical Research Centers Program of the Divisions of Research Resources, and by Grant CA-14917. National Institutes of Health.

36. Requests for reprints should be addressed to: P. Sunshine, M.D. Department of Pediatrics, Stanford University School of Medicine, Stanford, Calif. 94305 (USA).

37. Accepted for publication July 3, 1975 